\title{
Evaluation of Rheological Characteristics of Graphite Modified Bitumen
}

\author{
Odunayo Olayemi Oladunjoye ${ }^{\star 凶}$, Olugbenga Joseph Oyedepo, Ebenezer Omoniyi Olukanni and Sombo Philiph Akande \\ Federal University of Technology, Akure, Nigeria
}

Corresponding author's Email: oladunjoyeodunayo01@ gmail.com; (D) ORCiD: 0000-0003-2143-381X

\begin{abstract}
The level of performance of asphalt concrete has a close relationship with the properties of bitumen used. This research evaluates the rheological parameters of graphite modified bitumen. Index properties tests were conducted on bitumen and graphite to determine their suitability. Dynamic viscosity and dynamic shear rheometer were conducted on bituminous binder modified with four different proportion of graphite ranging from $2 \%$ to $10 \%$ by bitumen weight. Dynamic viscosity test was conducted on bitumen and graphite modified bitumen at temperature of $135^{\circ} \mathrm{C}$ and $165^{\circ} \mathrm{C}$ using Brookfield Viscometer. The rheological properties are centered on phase angle $(\delta)$ and complex shear modulus $\left(\mathrm{G}^{*}\right)$ which were determined on bitumen and graphite modified bitumen at temperature ranging from $52^{\circ} \mathrm{C}-70^{\circ} \mathrm{C}$ at $10 \mathrm{rad} / \mathrm{s}$ frequency using Dynamic Shear Rheometer in accordance with ASTM D7175-15. The storage modulus $\left(\mathrm{G}^{\prime}\right)$, loss modulus $\left(\mathrm{G}^{\prime \prime}\right)$ and rutting parameters were then evaluated from phase angle and complex shear modulus. The bitumen and graphite modified bitumen showed that graphite modified bitumen has the highest complex shear modulus and rutting parameter of $8984(\mathrm{kPa})$ and $33387(\mathrm{kPa})$ at $10 \%$ graphite content. The results of viscosity helped to determine the mixing and compaction temperatures. Dynamic shear rheometer test results determined the elastic and viscous behaviour at various temperature. The higher the complex shear modulus and rutting parameter the stiffer the binder will resist deformation and rutting.
\end{abstract}

Keywords: Graphite, Bitumen, Rheology, Characteristics

\section{INTRODUCTION}

Bitumen is one of the oldest known engineering materials that has been used in various ways, e.g., as adhesive, sealant, preservative, waterproofing agent and pavement binder (Polacco et al., 2006). Bitumen is a viscoelastic material; its rheological properties are very sensitive to temperature and rate of loading. In general, road pavement performance properties are mainly affected by the bitumen binder properties; a viscoelastic material has both elastic and viscous components of response: effecting of external force influence there is partly a permanent deformation (viscous part) and partly a reversible deformation (elastic part). Mezger (2006) deduced that one of the main aims of rheology is determining the relation between strains and stresses. The rheological properties of bitumen binders that have influence on material deformation and flow are generally expressed in term of the dynamic viscosity $(n *)$, the complex modulus $\left(\mathrm{G}^{*}\right)$ and the phase angle $(\delta)$.

Excessive increase in traffic (axle) load and variation in environmental factors contributes to distress or structural failure in highway pavement. The increase in axle loads repetition often leads to rutting and fatigue cracks, while increase or variation in environmental factors like temperature are the main cause of the cracks
(Honarmand et al., 2019). Traffic loading can cause tensile, compression, shear stresses, or a combination of them in different pavement points, depending on factors such as load size, contact surface, temperature, hardness, and pavement thickness. Typically, the repetition of these stresses and strains leads to damage the pavement. Fatigue cracks increases with the continuity of loading in the pavement system and ultimately expand into fatigue cracks. The accumulation of these cracks eventually disrupts the pavement. Therefore, the ability to predict the behavior of pavement against the phenomenon of fatigue is important. Since the fatigue phenomenon occurs more in the bitumen phase of the asphalt mixture, identifying the structure of the bitumen in the asphalt is very important to develop durability and life span (Bahia et al., 2001). Most engineers have attributed asphalt road failures to climatic conditions, but climatic conditions alone do not account for the deformation of roads but the choice of bituminous binder used as well (Vasudevan et al., 2012). Thus, there is a need for modifier or additives which offers a greater strength thereby reducing the fatigue cracking and rutting.

The possible use of the processed plastic bags as an additive in bituminous concrete mixes was investigated by (Justo et al., 2002). They observed that the penetration and ductility values of the modified bitumen decreased with 
the increase in proportion of the plastic additive, up to 12 $\%$ by weight. Therefore, the life of the pavement surfacing course using the modified bitumen is also expected to increase substantially in comparison to the use of ordinary bitumen.

Abdelaziz and Karim (2003) conducted a study on rheological evaluation of aged rubberized bitumen. The results showed that Crumb Rubber Modified (CRM) has an obvious significant effect on bitumen rheology by increasing complex shear modulus $G^{*}$ and decreasing phase angle $\delta$.

Likewise, Oyedepo and Oluwajana (2014) also investigated the properties of bitumen modified with used tyre. They deduced that Penetration value decreased with addition of $20 \%$ tyre while increase in softening point, viscosity, flash and fire point were obtained with the corresponding values of $80.9^{\circ} \mathrm{C}, 250.96 \mathrm{sec}$ and $189 / 280$ $12^{0} \mathrm{C}$ respectively.

Graphite Oxide (GO) was utilized with 80/100 penetration grade bitumen by Noor et al. (2015). They found that limited trial rheological result obtained for $0.1125 \mathrm{wt}$ GO modified bitumen showed that modification of bitumen with GO has improved its elastic capacity at higher temperature and lower frequency regime thus successfully can be used as bitumen modifier in future. The effect of graphite powder on the physical and rheological properties of the bitumen was investigated by Singh and Suman (2018). The result indicates an improvement in physical and rheological properties of the bitumen binder as illustrated through decrease in penetration value along with increase in softening point, viscosity and rutting resistance parameter with increase of additive content for both unaged as well as short-term aged samples.

Furthermore, Moreno-Navarro et al. (2018) conducted rheological and thermal tests on binders manufactured with different dosages of graphene flakes. The results indicate that the presence of graphene produces a more elastic response in asphalt binders. Wen et al. (2019) studied the effect of graphite on the electrical conductivity and rheological characterization of base asphalt. Experimental results indicate that the conductivity of asphalt binder improved with the increasing content of graphite. Moreover, asphalt binder exhibited improved viscoelastic response and resistance of rutting due to the addition of graphite. Although, research had been conducted on several additives used in modified asphalt concrete; the present research will therefore provide more information on rheological properties of graphite modified bitumen.
Two viscosity graded bitumen (VG30 and VG40) with $0.5,1.0,1.5$ and $2.0 \%$ of graphene by weight of bitumen was modified. The control and graphene modified bitumen were subjected to softening point test, storage stability test, multiple stress creep recovery (MSCR) test, and thermal conductivity test. The isochronal curves indicated reduction in loss factor and phase angle, while increase in complex shear modulus in graphene modified bitumen compared to control binder. The isochronal and multiple stress creep recovery test indicated that an optimum level of graphene was between 1.0 and $1.5 \%$ by weight of bitumen, which can be attributed to homogenous dispersion (Nazki et al., 2020).

\section{MATERIALS AND METHODS}

\section{Materials}

The materials used for this research was carefully selected to be of the highest grade and quality. The materials used for this research are as follows:

\section{Graphite}

Graphite is very soft, has a low specific gravity, and is relatively non- reactive and high electrical and thermal conductivity. The natural graphite used for this research was obtained from Kafanchan in Kaduna State, Nigeria (Figure 1).

\section{Bitumen}

Bitumen is a black, highly viscous and very sticky liquid or semi-liquid, found in some natural deposits. The bitumen used for this research is $60 / 70$ penetration grade. Bitumen penetration grade $60 / 70$ is standard penetration grade bitumen usually used as paving grade bitumen suitable for road construction. It was obtained from KK Hassan Nigeria Limited Akure, Ondo State (Figure 2).

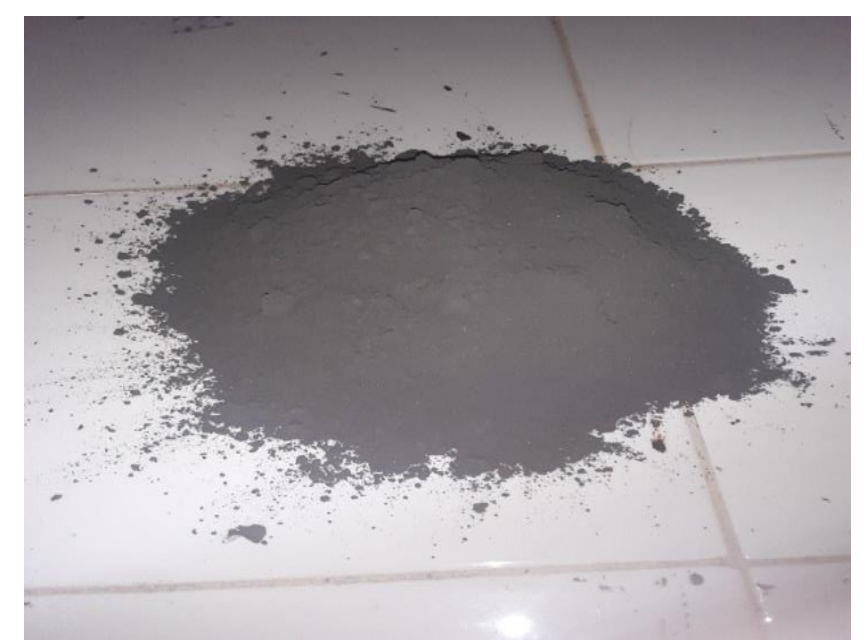

Figure 1. Powder Graphite 


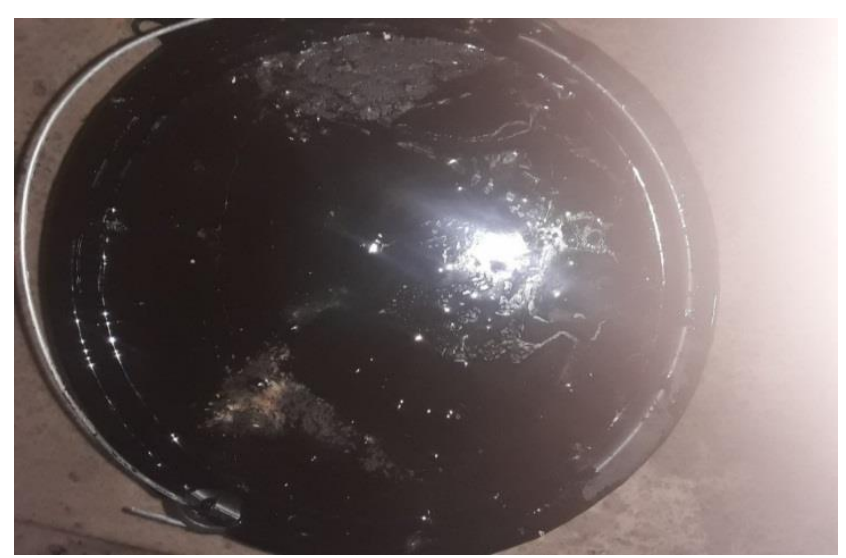

Figure 2. 60/70 Bitumen

\section{Methodology}

\section{Tests on bitumen}

Various laboratory tests were conducted on bitumen to check quality and different properties of bitumen for road construction. The tests were performed are as follows:

i. Penetration test (ASTM D5-05)

ii. Flash and fire point test (ASTM D92-18)

iii. Ductility test (ASTM D113-99)

iv. Softening point test (ASTM D36-06)

\section{Tests on graphite modified bitumen}

These are various tests performed on graphite modified bitumen to determine their rheological properties.

i. Dynamic Viscosity (ASTM D1084-21)

ii. Dynamic Shear Rheometer (ASTM D7175-15)

\section{Preparation of sample}

The production of graphite modified bitumen involved heating convectional bitumen to its melting point and continuously stirred. Then the convectional bitumen was then mixed with graphite at various percentage composition ranging from $2 \%$ to $10 \%$ by weight of convectional bitumen. The mixture was then mixed thoroughly until a perfect blend was obtained. The prepared binders with different graphite content were labelled GMB-2, GMB-4, GMB-6, GMB-8 and GMB-10.

\section{Rheological properties of binder}

The dynamic viscosity test was performed on graphite modified bitumen at temperature of $135^{\circ} \mathrm{C}$ and $165^{\circ} \mathrm{C}$ using Brookfield Viscometer. The rheological properties of bituminous binder were determined by dynamic shear rheometer in according to ASTM D7175-15 standard. The essential viscoelastic parameters obtained from dynamic shear rheometer test are the magnitude of the complex shear modulus $\left(\mathrm{G}^{*}\right)$ and the phase angle $(\delta)$. In this study, the rheological tests were performed with a Brookfield
DVIII programmable rheometer under controlled-stress conditions at $52^{\circ} \mathrm{C}, 58{ }^{\circ} \mathrm{C}, 64{ }^{\circ} \mathrm{C}, 70{ }^{\circ} \mathrm{C}$, and $10 \mathrm{rad} / \mathrm{s}$ of frequency using a $25 \mathrm{~mm}$ diameter plate and a $1 \mathrm{~mm}$ gap opening.

i. Phase Angle ( $\delta$ ): Phase angle is one of rheological parameter obtained directly from Dynamic Shear Modulus test that determines the viscoelastic properties of bituminous binder.

ii. Complex Shear Modulus $\left(\mathrm{G}^{*}\right)$ : Complex shear modulus is another rheological parameter obtained directly from Dynamic Shear Rheometer test. Complex modulus $\mathrm{G}^{*}$ can be considered as the total resistance of the binder to deformation at repeated shear load. The complex shear modulus comprises loss modulus (viscous) and elastic modulus (storage).

iii. Loss Modulus $\left(\mathrm{G}^{\prime \prime}\right)$ : The loss modulus represents the viscous part or the amount of energy dissipated in bituminous binder.

The loss modulus equation is given below:

Loss Modulus $=\mathrm{G}^{*} \operatorname{Sin} \delta$

iv. Storage Modulus $\left(\mathrm{G}^{\prime}\right)$ : This represents the energy stored in the elastic structure of the bituminous binder. If it higher than the loss modulus the material can be regarded as mainly elastic. The storage modulus is given in equation 2.

Storage Modulus $=\mathrm{G}^{*} \operatorname{Cos} \delta$

v. Rutting Parameter: Rutting parameter determines the resistance to rut of bituminous binder. The rutting parameter equation is given in equation 3 .

Rutting Parameter $=G^{*} / \operatorname{Sin} \delta$

\section{RESULTS AND DISCUSSION}

\section{Result of tests on bitumen}

\section{Penetration test (ASTM D5/D5M-20)}

This test is performed to determine the consistency and grade of bitumen, the result of this test is presented in Table 1.

Average Penetration Value $=\frac{71+69+67}{3}=69 \mathrm{dmm}$

The average penetration value of $69 \mathrm{dmm}$ obtained confirmed that the bitumen used is $60 / 70$ penetration grade bitumen.

Table 1. Penetration test

\begin{tabular}{lccc}
\hline & Sample 1 & Sample 2 & Sample 3 \\
\hline Final Penetration $(\mathrm{dmm})$ & 71.00 & 69.00 & 67.00 \\
Initial Penetration $(\mathrm{dmm})$ & 0.00 & 0.00 & 0.00 \\
Penetration $(\mathrm{dmm})$ & 71.00 & 69.00 & 67.00 \\
\hline
\end{tabular}




\section{Flash and fire point test (ASTM D92-18)}

The test is performed to determine the safe temperature up to which bitumen sample can be exposed. The result is shown in Table 2.

Average Flash Point $=\frac{288+289+287}{3}=288^{\circ} \mathrm{C}$

Average Fire Point $=\frac{317+316+318^{3}}{3}=317^{\circ} \mathrm{C}$

The flash point and fire point recommended value is between $280^{\circ} \mathrm{C}$ to $300^{\circ} \mathrm{C}$ and $300^{\circ} \mathrm{C}$ to $320^{\circ} \mathrm{C}$ according to ASTM D92-18. However, the average flash point obtained in this test is $288^{\circ} \mathrm{C}$ and the average fire point obtained is $317^{\circ} \mathrm{C}$, the values obtained are within the acceptable limits.

\section{Ductility test (ASTM D113-17)}

This test is done to determine the length to which bitumen can be extended before breaking. The result of this test is presented in Table 3 .

$$
\text { Average Ductility }=\frac{106+105+104}{3}=105 \mathrm{~cm}
$$

The recommended minimum value for ductility is 100 cm according to ASTM D113-17, the ductility value obtained exceeds the minimum value.

\section{Softening point test (ASTM D36-20)}

The result of softening point performed bitumen determine the temperature at which a bituminous sample becomes soft; the result is presented in Table 4 .

Average Softening Temperature $=\frac{46+48+49}{3}=47.7^{\circ} \mathrm{C}$

The temperature at which the tested bitumen softens is $47.7^{\circ} \mathrm{C}$, which is above the minimum value of $45^{\circ} \mathrm{C}$ specified by ASTM D36-20.

Graphite impact value and graphite crushing value (BS 812-110-1990)

Graphite Impact Value (GIV) performed determined the percentage of fines produced from the graphite sample after subjecting it to a standard amount of impact. The result of GIV test is contained in Table 6.

Average GIV $(\%)=\frac{17.54+19.00+18.70}{3}=18.43 \%$; and

Average GCV $(\%)=\frac{25.39+25.69+28.00}{3}=26.36 \%$

From Table 6, the average percentage weight of GIV is recorded $18.43 \%$ which falls within the GIV between required ranges of 15 to $20 \%$. Similarly, the average percentage weight of GCV is recorded $26.36 \%$ which falls within the GIV between required ranges of 25 to $28 \%$.

Table 2. Flash and fire point test

\begin{tabular}{lcccccc}
\hline & \multicolumn{2}{c}{ Sample 1 } & \multicolumn{2}{c}{ Sample 2 } & \multicolumn{2}{c}{ Sample 3 } \\
\cline { 2 - 7 } & Flash Point & Fire Point & Flash Point & Fire Point & Flash Point & Fire Point \\
\hline Final Temperature $\left({ }^{\circ} \mathrm{C}\right)$ & 288 & 317 & 289 & 316 & 287 & 318 \\
\hline Initial Temperature $\left({ }^{\circ} \mathrm{C}\right)$ & 0 & 0 & 0 & 0 & 0 & 0 \\
\hline Temperature $\left({ }^{\circ} \mathrm{C}\right)$ & 288 & 317 & 289 & 316 & 287 & 318 \\
\hline
\end{tabular}

Table 3. Ductility test

\begin{tabular}{lccc}
\hline & Sample 1 & Sample 2 & Sample 3 \\
\hline Ductility (cm) & 106 & 105 & 104 \\
\hline
\end{tabular}

Table 4. Softening point test

\begin{tabular}{cccc}
\hline & Sample 1 & Sample 2 & Sample 3 \\
\hline Softening Temperature $\left({ }^{\circ} \mathrm{C}\right)$ & 46 & 48 & 49 \\
\hline
\end{tabular}

Table 5. Standard specification of bitumen properties

\begin{tabular}{lccc}
\hline Test & Unit & Limit & ASTM Test Method \\
\hline Penetration @ 25 ${ }^{\circ} \mathrm{C}$ & $\mathrm{D}$ & $60-70$ & $\mathrm{D} 5$ \\
\hline Softening Point & ${ }^{\circ} \mathrm{C}$ & $49-56$ & $\mathrm{D} 36$ \\
\hline Ductility @ 25 ${ }^{\circ} \mathrm{C}$ & $\mathrm{Cm}$ & $100 \mathrm{~min}$ & $\mathrm{D} 113$ \\
\hline Flash Point & ${ }^{\circ} \mathrm{C}$ & $280 \mathrm{~min}$ & $\mathrm{D} 92$ \\
\hline Fire Point & ${ }^{\circ} \mathrm{C}$ & $320 \mathrm{max}$ & $\mathrm{D} 90$ \\
\hline Viscosity & $\mathrm{Sec}$ & $300 \mathrm{~min}$ & $\mathrm{D} 2170$ \\
\hline Water in Bitumen & $\%$ & 5 max & $\mathrm{D} 95$ \\
\hline
\end{tabular}

Source: Asphalt Institute (1997)

Table 6. Graphite impact and crushing value test

\begin{tabular}{lccc|ccc}
\hline & & GIV & & GCV \\
\hline & Sample 1 & Sample 2 & Sample 3 & Sample 1 & Sample 2 & Sample 3 \\
\hline Initial Weight $(\mathbf{g})$ & 546.90 & 551.30 & 596.70 & 490.40 & 514.50 \\
\hline Final Weight (g) & 95.90 & 104.80 & 112.00 & 124.50 & 132.20 \\
\hline GIV $(\%)$ & 17.54 & 19.00 & 18.70 & 25.39 & 25.69 & 147.30 \\
\hline
\end{tabular}




\section{Rheological characterization of graphite modified bitumen}

Dynamic viscosity of graphite modified bitumen

The viscosity test was done to evaluate the viscosity of graphite-modified bitumen using Brookfield viscometer. The results of viscosities of graphite modified bitumen at $135^{\circ} \mathrm{C}$ and $165^{\circ} \mathrm{C}$ is given in Figure 3. The results presented in Figure 4 show that increase in graphite content causes a steady increased in the viscosities at both temperatures. The results show that the viscosity for all binders decreased as the temperature increased from $135^{\circ} \mathrm{C}$ to $165^{\circ} \mathrm{C}$ respectively. Moreover, the highest viscosity value of 570.50 (cp) was obtained at $10 \%$ and lowest viscosity value of 300.90 (cp) at $0 \%$ for $135^{\circ} \mathrm{C}$ likewise highest viscosity of 157.04 (cp) was obtained at $10 \%$ and lowest viscosity of 78.02 (cp) at $0 \%$ for $165^{\circ} \mathrm{C}$. This revealed that graphite helped to lower the mixing and compaction temperature of bituminous binder.

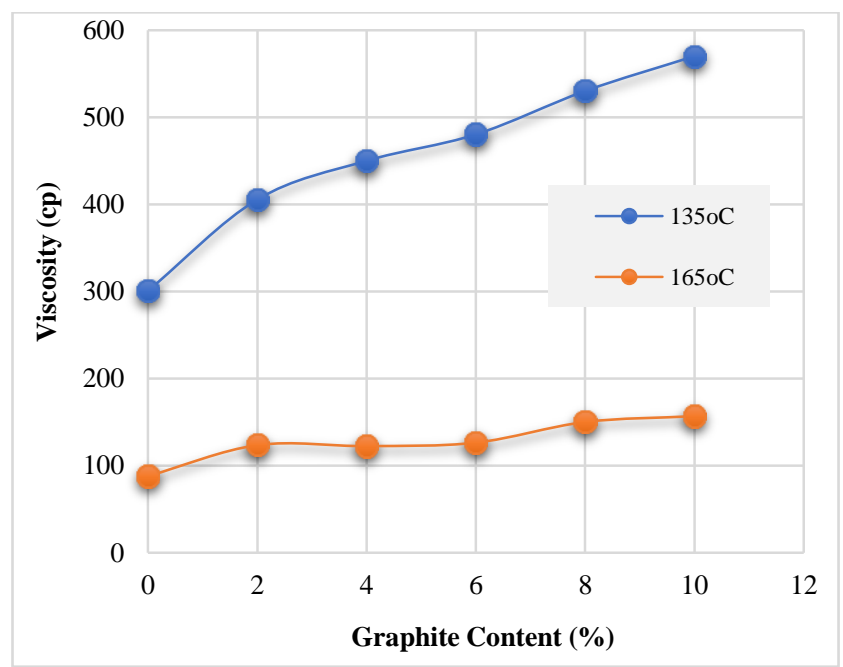

Figure 3: Effect of Graphite Content on Viscosity at $135^{\circ} \mathrm{C}$ and $165^{\circ} \mathrm{C}$

\section{Dynamic shear rheometer of graphite modified bitumen}

The dynamic shear rheometer test values of the bituminous binders were determined according to ASTM D7175-15 standard using Dynamic Shear Rheometer. The essential rheological parameters obtained from dynamic shear rheometer test are the magnitude of the complex shear modulus $\left(\mathrm{G}^{*}\right)$ and the phase angle $(\delta)$. Complex Shear modulus $\left(\mathrm{G}^{*}\right)$ and phase angle $(\delta)$ are generally used in evaluating the deformation and rutting performance of asphalt binder.

\section{Phase angle of graphite modified bitumen}

The phase angle is one of the rheological properties which determine the viscoelastic properties of bituminous binder. The phase angle result ranging from $52^{\circ} \mathrm{C}$ to $70^{\circ} \mathrm{C}$ temperature is shown in Figure 4.

The phase angle of graphite modified bitumen result shows that decreases in the phase angle $(\delta)$ values depend on increase in graphite content. The addition of graphite significantly decreased the binder phase angle $(\delta)$ values. Unmodified bitumen has the highest phase angle value of $42.45^{\circ}$ at $70^{\circ} \mathrm{C}$ and lowest phase angle value of $35.50^{\circ}$ at $52^{\circ} \mathrm{C}$ while modified bitumen has the highest value of $39.22^{\circ}$ at $70^{\circ} \mathrm{C}$ for $2 \%$ and lowest phase angle value of $15.6^{\circ}$ at $52^{\circ} \mathrm{C}$ for $10 \%$ graphite content. The phase angle ranges from zero degrees to ninety degrees and is the corresponding lag between the elastic and the viscous response. It can be seen from Figure 4 that the phase angle of both modified and unmodified binder have greater elastic component. Moreover, modification of binder improved the elastic respond. This indicates that graphite modified bitumen have a better deformation resistance since its more elastic than the convectional bitumen.

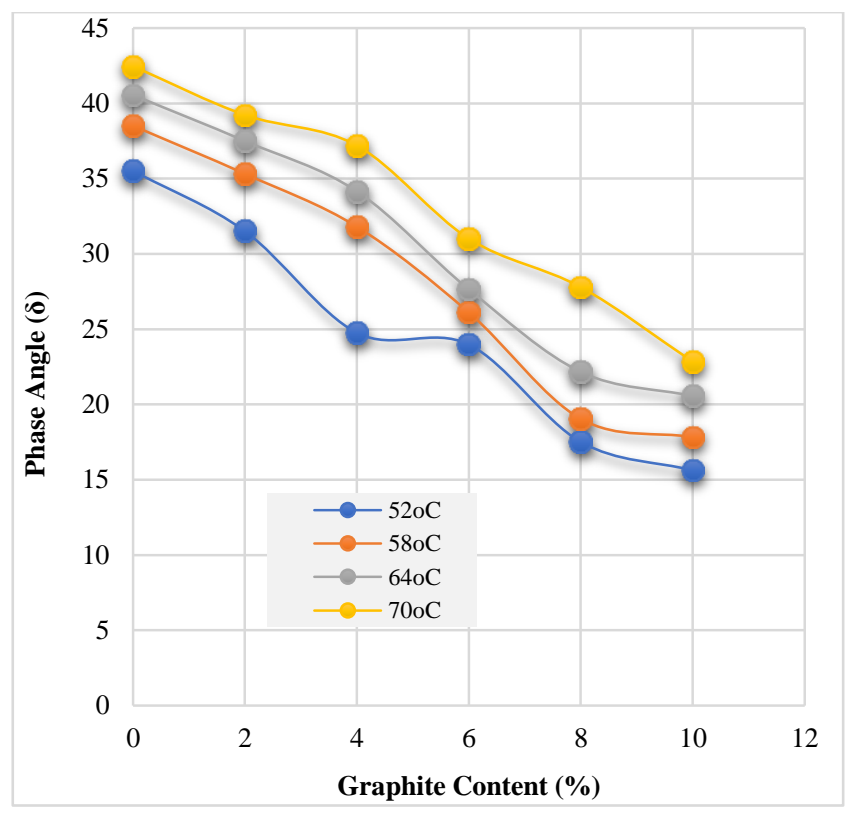

Figure 4: Phase angle against Graphite Content

\section{Complex shear modulus of graphite modified} bitumen

The complex shear modulus $\left(\mathrm{G}^{*}\right)$ considered the sample's total resistance to deformation when repeatedly shared. Complex shear modulus $\left(\mathrm{G}^{*}\right)$ comprises of Storage modulus $\left(G^{\prime}\right)$ and Loss modulus $\left(G^{\prime \prime}\right)$. The complex shear modulus result is presented in Figure 5. 
It can be seen from Figure 5 that increase in complex shear modulus value continued as the percentage of graphite increased from $2 \%$ to $10 \%$. Unmodified bitumen has the highest complex shear modulus of $2479(\mathrm{kPa})$ at $52^{\circ} \mathrm{C}$ and lowest complex shear modulus of $846(\mathrm{kPa})$ at $70^{\circ} \mathrm{C}$ while modified bitumen has the highest complex shear modulus value of $8984(\mathrm{kPa})$ at $52^{\circ} \mathrm{C}$ for $10 \%$ and lowest value of $874(\mathrm{kPa})$ at $70^{\circ} \mathrm{C}$ for $2 \%$ graphite content. Figure 5 reveals that the modified bituminous binders have a better resistance to deformation than unmodified binder. The higher the complex shear modulus the stiffer the bituminous binders will resist deformation.

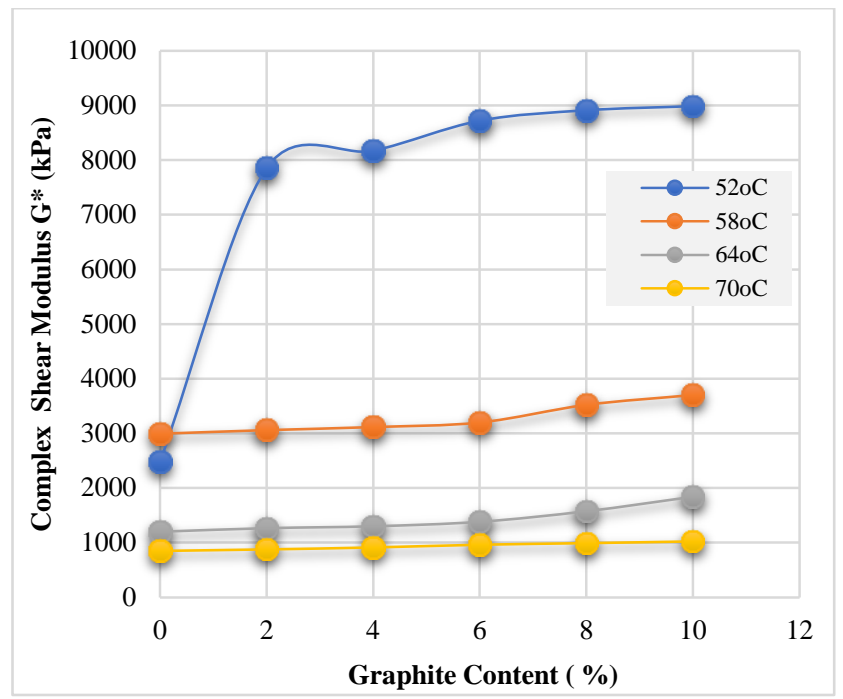

Figure 5. Complex Shear Modulus vs Graphite Content

\section{Storage and loss of graphite modified bitumen}

The loss and storage modulus of binders which are measures of the energy dissipated and energy stored by bituminous binder. The result storage and loss modulus are presented in Figures 6 and 7.

Figure 6 and 7 reveals that energy gained by both modified and unmodified bituminous binder are much more than energy dissipated. Moreover, the energy gained by modified binders were much more than unmodified binder. This attribute to the fact that modified binder will return to its original shape faster than unmodified binder. Figure 8 shows the rutting parameter of graphite modified bitumen.

The result presented in Figure 8 contains the rutting parameter of graphite modified bitumen. The rutting parameters of the graphite modified binder increased significantly with increase in graphite content. Figure 8 revealed that modified binders have a better rutting resistance than unmodified binder. This indicate that modified binder will resist traffic axle load for a longer period than unmodified binder.

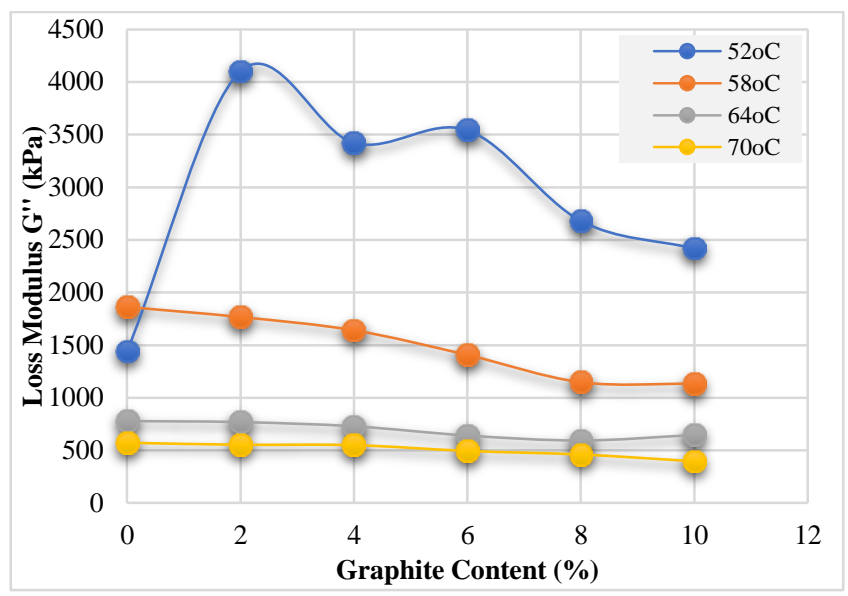

Figure 6. Loss Modulus against Graphite Content

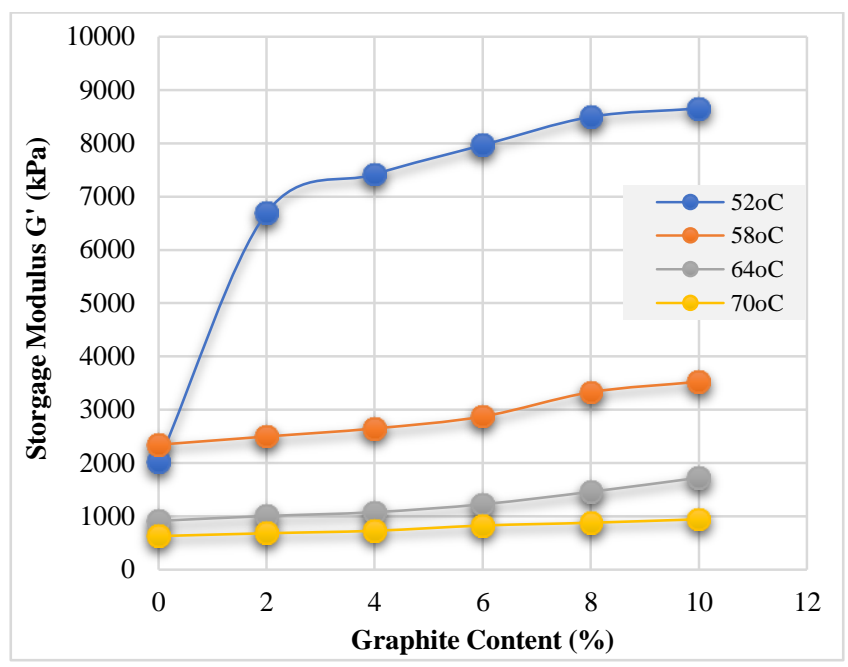

Figure 7. Storage Modulus against Graphite Content

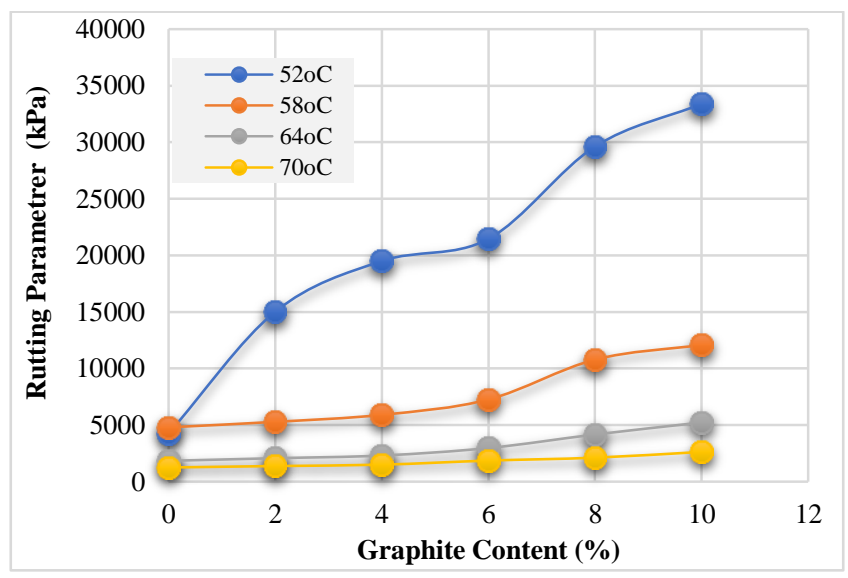

Figure 8: Rutting Parameter Against Graphite Content 


\section{CONCLUSION}

Based on laboratory investigations and results obtained from this research, the following conclusions from binder tests on both modified and unmodified binders were drawn:

i. Modified binder has the ability to store energy than unmodified binder. This can be attributed to the fact that modified binder will return to its original shape faster than unmodified binder at any point when axle load is removed.

ii. Modified binder has a better resistance to deformation and rutting than unmodified bitumen. This means that the modified binder will resist traffic axle load for a longer period than unmodified binder.

Summary, it is obvious that graphite content played a significant role in influencing the performance and rheological properties of graphite bitumen binders. Also, graphite improved the rutting and fatigue resistance of bituminous binder.

\section{DECLARATIONS}

\section{Authors' contribution}

E. Olukanni and S. Akande source for the materials and performed the experiment. O.Oladunjoye wrote the manuscript and anlyzed the data. O.Oyedepo critically revised the manuscript for intellectual contents. All authors read and approved the final manuscript

\section{Conflict of interest}

There is no conflict of interest with any third party.

\section{REFERENCES}

Abdelaziz M, Karim MR. (2003). Rheological evaluation of ageing properties of rubber crumb modified bitumen. Journal of the Eastern Asia Society for Transportation Studies. 5:820-33. https://www.hindawi.com/journals/amse/2013/239036

Bahia HU, Zhai H, Zeng M, Hu Y, Turner P. (2001). Development of binder specification parameters based on characterization of damage behavior (with discussion). Journal of the Association of Asphalt Paving Technologists. 70:442-470. https://trid.trb.org/view/720136

Honarmand M, Tanzadeh J, Beiranvand M. (2019). Bitumen and its modifier for use in pavement engineering. Sustainable
Construction and Building Materials. 2019 Mar 13:249-70. DOI: $\quad$ https://doi.org/10.5772/intechopen.82489 ; https://econpapers.repec.org/RePEc:ito:pchaps:170965

Justo CEG and Veeraragavan A (2002). "Utilization of Waste Plastic Bags in Bituminous Mix for Improved Performance of Roads". Centre for Transportation Engineering, Bangalore University, Bangaore, India. www.sciepub.com/reference/260211

Mezger TG (2006). The Rheology Handbook. 2nd edition. Vincentz Network, ISBN 3-87870-174-8. Journal of Modern Physics, $\quad$ Vol.4, $\quad$ No.10B https://www.scirp.org/(S(i43dyn45teexjx455qlt3d2q))/journ al/home.aspx?issueid $=3894$

Moreno-Navarro F, Sol-Sánchez M, Gámiz F, Rubio-Gámez MC. (2018). Mechanical and thermal properties of graphene modified asphalt binders. Construction and Building materials. $\quad 180$ : 265-74. DOI: https://doi.org/10.1016/j.conbuildmat.2018.05.259

Nazki MA, Chopra T, Chandrappa AK. (2020). Rheological properties and thermal conductivity of bitumen binders modified with graphene. Construction and Building Materials. 238: 117693. https://doi.org/10.1016/j.conbuildmat.2019.117693

Noor ZH, Ng CA, Salah EZ and Pei IL (2015). Use of graphene oxide as a bitumen modifier: An innovative process optimization study. Advanced Materials Research, 1105: 365-369.

DOI: https://doi.org/10.4028/www.scientific.net/AMR.1105.365

Oyedepo OJ, Oluwajana SD. (2014). Evaluation of properties of bitumen modified with waste tyre. Nigerian Journal of Technology. 33(1):119-24. DOI: https://doi.org/10.4314/njt.v33i1.16

Polacco G, Stastna J, Biondi D, Zanzotto L. (2006). Relation between polymer architecture and nonlinear viscoelastic behavior of modified asphalts. Current Opinion in Colloid \& Interface Science. 11(4): 230-45. DOI: https://doi.org/10.1016/j.cocis.2006.09.001

Singh PK and Suman SK. (2018). Influence of graphite on the physical and rheological properties of bituminous binder before and after short-term ageing. Construction and Building Materials. 192: 866-73. DOI: https://doi.org/10.1016/i.conbuildmat.2018.10.122

Vasudevan R, Sekar AR, Sundarakannan B, Velkennedy R. (2012). A technique to dispose waste plastics in an ecofriendly way-Application in construction of flexible pavements. Construction and Building Materials. 28(1): 311-20.

DOI: https://doi.org/10.1016/j.conbuildmat.2011.08.031

Wen X, Wang H, Yang J. (2019). Electrical Conductivity and Rheological Properties of Asphalt Binder Containing Graphite. In CICTP 2019 (pp. 964-974). DOI: https://doi.org/10.1061/9780784482292.086 